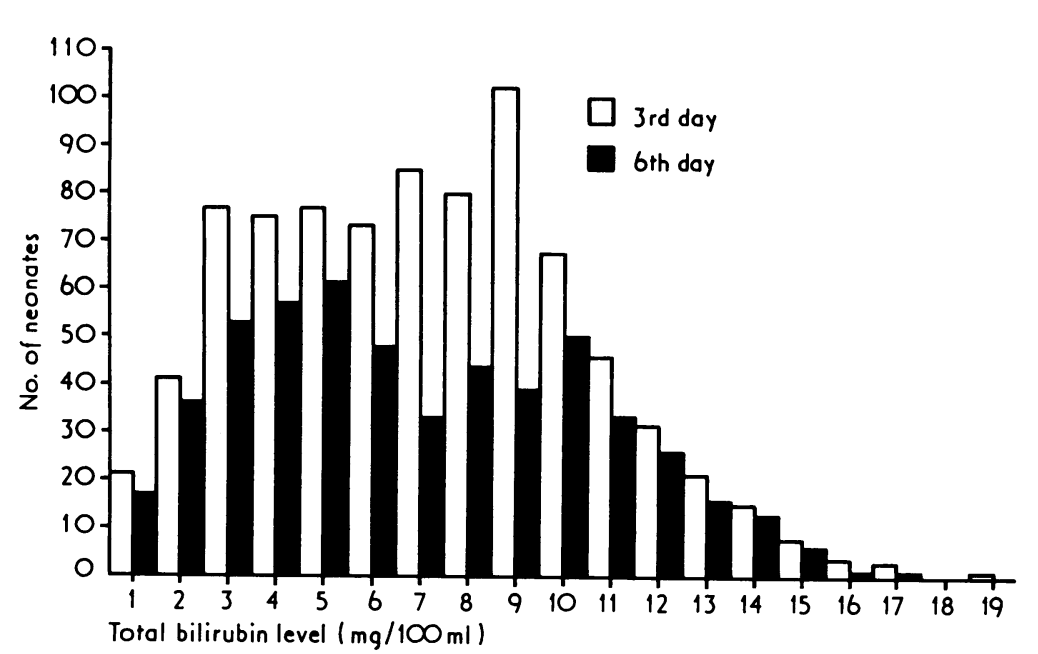

of oxytocin in labour and an increase in the mean bilirubin concentration in the neonates. Our results ${ }^{1}$ obtained from examination of mean bilirubin concentrations in a prospective study of 1,353 labours and neonates agree with the relationship they have shown, but we differ from the conclusion drawn. Possible explanations for this come to mind and deserve comment:

(1) In the study by Dr. Gould and his colleagues serum bilirubin concentrations were estimated on blood taken from the cord at birth and from the baby on the sixth day of life. We suggest that the timing of these blood samples was not ideal for the purpose of this study. It is not to be expected that the bilirubin concentration wou.d be raised in cord blood specimens, whereas by the sixth day of life it can be shown that it has passed its peak and is decreasing. The figure shows the distribution of mean total bilirubin concentrations on the third and sixth days of life in our series of 815 neonates resulting from labours induced or accelerated with oxytocin. It will be seen that on the third day the peak incidence of neonates is associated with a bilirubin concentration of $8 \mathrm{mg} / 100 \mathrm{ml}$ whereas by the sixth day the peak incidence of neonates has a bilirubin concentration of only $5 \mathrm{mg} / 100 \mathrm{ml}$. This suggests that in most neonates the bilirubin concentrations are falling by the sixth day. A similar trend is reported by McConnell et al..$^{2}$ who found that on the fifth day serum bilirubin concentrations were $32 \%$ lower than on the third day in bottle-fed infants.

(2) Several workers ${ }^{1-4}$ other than Gould and his colleagues have tried to show an association between a raised mean neonatal bilirubin concentration and the maternal administration of oxytocin. With the exception of Davies et al. ${ }^{3}$ none have yet found a significant relationship between the use of maternal oxytocin in labour and the mean bilirubin concentration of the neonates. Even Davies et al. claimed only that the association was of minimal significance $(\mathbf{P}<$ 0.05 , method of statistical analysis not stated). However, after labours induced by amniotomy and oxytocin we have shown that the mean total dose of oxytocin received by the mothers whose babies were normal (bilirubin concentration $<12 \mathrm{mg}$ / $100 \mathrm{ml}$ ) was only $9.91 \mathrm{U}$, whereas mother of neonates with hyperbilirubinaemia (bilirubin concentration $>12 \mathrm{mg} / 100 \mathrm{ml}$ ) received a mean total dose of $18.77 \mathrm{U}$ of oxytocin. This difference between the total doses of oxytocin administered is highly significant ( $t$ test : $\mathrm{P}<0.001$ ). Furthermore, we found that the proportion of neonates who developed hyperbilirubinaemia increased in direct relation to the increasing total dose of oxytocin administered. This association was also highly significant (Wilcoxon's test of differences between mean ranks: $\mathrm{P}<0.001)$.

Our results support the association between the use of oxytocin in labour and the subsequent development of mild neonatal jaundice, though other factors are involved.-I am, etc.,

BRIAN ALDERMAN JOHN M. BEAZLEY

Department of Obstetrics and Gynaecology,

University of Liverpool

Beazley, J. M., and Alderman, B., fournal of Obstetrics and Gynaecology of the British Commonwealth. In press. 2 McConnelth. J. B., Glasgow, J. F. T., and McNair,

Davies, D. P., et al., British Medical fournal, 1973, 3, 476 .

Ghosh, A., and Hudson, F. P., Lancet, 1972, 2,
823.

\section{Minocycline and $\beta$-haemolytic Streptococci}

SIR,-Resistance of $\beta$-haemolytic streptococci to the tetracyclines can be a clinical problem..$^{1-3}$ Therefore it is of interest that a new analogue of tetracycline, minocycline (Minocin, Lederle), is now available with reports of its activity against tetracyclineresistant streptococci. ${ }^{45}$ To compare in vitro this activity with that of tetracycline 63 $\beta$-haemolytic streptococci were obtained from a variety of clinical sources. Dilutions of each antibiotic were made and added to $10 \%$ horse-blood agar (Oxoid, Base No. 2) to yield culture plates with a range of final antibiotic concentrations from 0.3 to 20 $\mu \mathrm{g} / \mathrm{ml}$. The test organisms were grown overnight at $37^{\circ} \mathrm{C}$ in Todd-Hewitt broth (Oxoid) and were diluted $1 / 50$ before each was "spotted" on to an antibiotic-free control plate and on to each antibiotic-concentration plate. After overnight incubation at $37^{\circ} \mathrm{C}$ the inoculated plates were examined for the presence or absence of growth.

With ordinary dosage of tetracycline $(250$ $\mathrm{mg}$ six-hourly) maximal blood levels of $2-4 \mu \mathrm{g} / \mathrm{ml}$ may be expected, ${ }^{6}$ whereas for minocycline at recommended dosage (200 $\mathrm{mg}$ "loading" and $100 \mathrm{mg}$ 12-hourly thereafter) the mean serum concentration over a six days' course is between 1.53 and 2.30 $\mu \mathrm{g} / \mathrm{ml}^{7}$ Therefore to assess potential resistance among the test organisms "threshold" minimum inhibitory concentration values were adopted of $2.5 \mu \mathrm{g} / \mathrm{ml}$ tetracycline and $1.25 \mu \mathrm{g} / \mathrm{ml}$ minocycline, with the results shown in the table.

\begin{tabular}{|c|c|c|}
\hline \multirow{2}{*}{$\begin{array}{c}\text { No. of } \\
\text { Strains Tested }\end{array}$} & \multicolumn{2}{|c|}{ No. $(\%)$ of Strains inhibited by } \\
\hline & $\begin{array}{l}\text { Tetracycline } \\
\leqslant 2.5 \mu \mathrm{g} / \mathrm{ml}\end{array}$ & $\begin{array}{l}\text { Minocycline } \\
\leqslant 1 \cdot 25 \mu \mathrm{g} / \mathrm{ml}\end{array}$ \\
\hline $\begin{array}{rr}\text { Group A } & 33 \\
\text { B } & 15 \\
\text { C } & 9 \\
\text { G } & 6\end{array}$ & $\begin{aligned} 16 & (48) \\
2 & (13) \\
5 & (55) \\
3 & (50)\end{aligned}$ & $\begin{aligned} 22 & (66) \\
2 & (13) \\
5 & (55) \\
3 & (50)\end{aligned}$ \\
\hline
\end{tabular}

In vitro minocycline seems to have some advantages over tetracycline against group A $P$-haemolytic streptococci but not against strains of groups B. C, or G. However, it is debatable whether or not this represents any real advantage in vivo.- I am, etc.,

Rosemary E. T. MCGILI

Microbiology Department,
Ayrshire Central Hospital,

Irvine

1 Garrod, L. P., Lambert, H. P., and O'Grady, F. Antibiotic and Chemotherapy, 4th edn., p. $15 i$. Edinburgh, Churchill Livingstone, 1973.
Robertson, M. H., British Medical fournal, 1973, 4,84 . 3 Fallon, R. J., British Medical fournal, 1973, 4,

Steigbigel, N. N., Reed, C. W., and Finland, M.,
American fournal of American 179.

5 Garrod, L. P., Lambert, H. P., O'Grady, F. Antibiotic and Chemotherapy, 4th edn., p. 161 . Edinburgh, Churchill Livingstone, 1973.

6 Garrod, L.' P., Lambert, H. P., O'Grady, F. Antibiotic and Chemotherapy, 4th edn., p. 154. 7 Frisk, A. R., Turchall, Livingstone, 1973 . and Chemotherapy, 1969, 8, 335 .

\section{Sun, Wind, Sand and the Skin of Children}

SIR,-Your leading article (13 July, p. 72) and the letter from Dr. E. J. Moynahan (10 August, p. 410) prompt report of the observation that infants suffering from atopic lecions of the skin or napkin dermatitis need not suffer exacerbation of their symptoms when involuntarily exposed to the desiccating action of sun, wind, and sand when on holiday.

The mothers of 11 patients (age range 10 months to 6 years) with symptoms currently in remission expressed anxiety, from previous experience, that exacerbation would occur during forthcoming seaside holidays. This group and five other children (age range 4 months to 2 years) were questioned about the provision of adequate sun protection (clothing, hat, "sun cream") and relevant advice was given -this generally reinforcing previous sensible practice. In addition, application of Parfenac cream (bufexamac 5\%) applicaand evening was prescribed, all 16 child morning and evening was prescribed, all 16 children having previously achieved the current remission of their ymptoms with this preparation (maximum time in

When seen subsequently 12 children $(75 \%)$ had remained symptom-free, $3(18 \cdot 75 \%)$ had had a flare-up equivalent to the original presenting condition, and $1(6.25 \%)$ reported eczematous area in a new site (the knees) which lasted for the duration of the holiday which had three with a severe flare-up returned ab only. The their prescribed ointe-up returned about $75 \%$ of group who had not prent and all were from the group who had not previously experienced a flareup of symptoms under holiday conditions. All the remainder returned quantities suggesting that the preparation had been used as prescribed.

In addition to the advantage of being a non-steroid, this anti-inflammatory agent has a bland, moisturing base that is not painful on application and consequently is generally well tolerated by children. While sensible clothing and gradual exposure remain the best method of avoiding the adverse effects 
of exposure to sun and wind, this smal group of previously affected children appears to have benefited significantly from the addition of this medication to their skin. -I am, etc.,

A. J. MaCnab University College Hospital Medical School,
London W.C.1

\section{Continuous Insulin Infusion}

SIR,-We have read with great interest the papers by Dr. M. McB. Page and others, Dr. Warren Kidson and others, and Dr. P. F. Semple and others on the treatment of hyperglycaemia, ketoacidosis, and diabetic coma by continuous insulin infusion (29 June, pp. 687, 691, and 694). These authors rightly emphasize the importance of continuous insulin infusion in these emergency situations. Though the practice of giving large, frequent doses of insulin in these conditions has been criticized the advantages of continuous insulin infusion have not been generally recognized. Perhaps these reappraicals of infusion therapy together with recent advances in medical technology may change the situation.

Interestingly enough the value of continuous infusion as the treatment of choice for diabetic hyperglycaemia, ketoacidosis, precoma, and coma becomes obvious when one considers the working of the artificia B-cell for the automatic control of blood glucose in diabetics. When such a system of a glucose-regulated insulin infusion (consisting of a Technicon-AutoAnalyzer, a micro computer, insulin and glucose infusion pumps, and a teleprinter) is used the patien requires from 600 to $1,000 \mu \mathrm{U}$ of insulin per minute for about 90 to 120 minutesthat is, so long as blood glucose levels have not returned to normal. ${ }^{1-3}$ Afterwards only small doses of insulin are needed to maintain normal blood gluoose, despite the patient being allowed unlimited food intake as soon as possible. Bicarbonate and potassium are given in usual amounts. In five cases treated so far in this way no untoward side effects have been recorded despite the rapid lowering of blood glucose produced by our technique. ${ }^{4}-W e$ are, etc.,

Department of Internal Medicine,

University of Ulm,

Germany

E. F. PFEIFFER

C. THUM

Life Science Instruments,

Miles Laboratories, Inc.

Elkhart, Indiana,

Albisser, A. M., et al., Diabetes, 1973, 22, 2 Albisser, A. M., et al., 1974. Personal com-

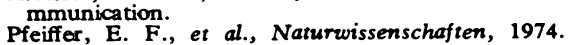
Pfeiffer, E.
In press.

In press.
Pfeiffer, E. F., et al., Hormone and Metabolic Peiffer, E. Fi, et al., H,
Research, In press.

\section{Zoster in Three Children in Family}

SIR,-The three children of one family, all girls, suffered an attack of varicella in 1966 at a time when the youngest may have been carrying some maternal immunity to the disease. Within a few years each developed zoster (see table).

In the 3,600-3,800 population of our general practioe zoster occurs at a rate of 0.7 per 1,000 of persons under 10 years old

\begin{tabular}{c|c|c|c|c}
\hline Patient & $\begin{array}{c}\text { Date of } \\
\text { Birth }\end{array}$ & $\begin{array}{c}\text { Age at } \\
\text { Varicella }\end{array}$ & $\begin{array}{c}\text { Age at } \\
\text { Zoster }\end{array}$ & $\begin{array}{c}\text { Interval between } \\
\text { Varicella and Zoster }\end{array}$ \\
\hline 1 & $\begin{array}{c}\text { March } 1959 \\
\text { Oct. 1960 } \\
\text { Dec. 1965 }\end{array}$ & $\begin{array}{l}7 \text { years } \\
6 \text { years } \\
4 \text { months }\end{array}$ & $\begin{array}{c}10 \text { years } \\
8 \text { years } \\
22 \text { months }\end{array}$ & $\begin{array}{c}3 \text { years } \\
3 \text { years } \\
18 \text { months }\end{array}$ \\
\hline
\end{tabular}

annually (patient 1 had only just passed her tenth birthday). The chance occurrence of zoster in two siblings is therefore not common, and in fact there have been no other cases of zoster in young siblings among the 350 cases of zoster encountered during 28 years continuous study here. If two cases in the same family are uncommon the occurrence of zoster in three young siblings must be so rare as to fall under the strong suspicion of not being a chance event. Should it not be fortuitous it may offer an opportunity for a better understanding of the mechanisms by which latent zoster-varicella virus is reactivated from latency.

I hope that others with records of siblings, especially children, with zoster will publish the details.-I am, etc.,

Cirencester

R. EDgAR HOPE-SIMPSON

\section{Trasylol for Pancreatitis}

SIR,-The leading article (20 July, p. 133) on Trasylol (aprotinin) therapy in the management of acute pancreatitis leaves one with the impression that your advocacy for the use of this expensive substance was based on the findings of a recent double-blind trial. ${ }^{1}$ We have previously commented on the high mortality rate of $25 \%$ in the control group of patients in that trial. ${ }^{2}$ We have found, in a prospective survey of acute pancreatitis, ${ }^{3}$ a mortality rate of $11.1 \%$ for 90 patients (out of a total 140) who met the criteria of a first attack of idiopathic pancreatitis or gall stone-associated acute pancreatitis. These 90 patients were all managed conservatively without the use of Trasylol (or glucagon). It is therefore our distinct impression that the case for Trasylol remains to be proved against a control group with a much lower mortality rate than $25 \%$

A further point, on the incidence of the disease, is worthy of comment. Our experience is that acute pancreatitis is a comcon cause of emergency surgical admission. The catchment population of Glasgow Royal Infirmary is about 500,000 and currently more than 50 patients a year are admitted suffering from acute pancreatitis. -We are, etc.,

C. W. IMRIE

Department of Surgery,
Royal Infirmary, Glasgow

L. H. BLUMGART

1 Trapnell, J. E., et al., British fournal of Surgery, 1974, 61, 177.

2 Imrie, C. W., and Blumgart, L. H., British Medical Fournal, 1974, 1, 38 Medical fournal, 1974, 1, 38.
publication., and Whyte, A. S. Submitted for

\section{Death after E.C.T.}

SIR,-I was interested in Dr. Joan $R$. Gomez's report of a death after E.C.T. (6 July, p. 45). She did not discuss the question of plasma cholinesterase. Hodges and Harkness ${ }^{1}$ pointed out that prolonged apnoea after the administration of suxamethonium was primarily due to a low level of serum pseudocholinesterase. They associated low levels with patients who were clinically "ill," and they maintained that there was no particular correlation between subnormal pseudocholinesterase levels and any particular disease but rather with the general physical state. Since then much work has been done and numerous papers have ascociated a low serum cholinesterase with many diseases. There is also the rare person who possesses the silent gene and who has virtually no cholinesterase activity.

Other work, using inhibitors of pseudocholinesterase (dibucaine and sodium fluoride), has identified at least 10 cholinesterase genotypes. ${ }^{2}$ Thus a person in whom the quantitative estimation of serum cholinesterase may be normal may belong to one of these subgroups and his cholinesterase be unable to hydrolyse suxamethonium. Most of these rare groups are identified by their dibucaine and fluoride numbers but some very rare ones can be discovered only by genetic studies of the families. The commonest is the co-called "atypical" group, which occurs in only one out of 3,000 persons. The other groups include the subgroup $I_{1}$ of the "intermediate" group and the homozygous fluoride-resistant group. Not all theie groups show the same degree of apnoea after suxamethonium but they are all at risk.

Some cases with apnoea do not fall in any of these groups, and possibly if different inhibitors (for example, sodium chloride or tertial butyl alcohol) were used further subgroups at risk might be discovered. Also possibly some of the unexplained cases of apnoea may be associated with a completely different enzyme group. The non-specific aliesterases, for example, detoxicate toxic substances and drugs such as suxamethonium, but in man aliesterases are normally at a low level and it would be difficult to incriminate them.

Dr. Gomez raised the question of the danger of using amitryptiline. This certainly has various cardiovascular effects. It must, however, be remembered that amitryptiline (in common with other tricyclic antidepressants) has a chemical structure similar to the cholinesterase inhibitor dibucaine. In fact amitryptiline is apparently an effective inhibitor of serum cholinesterace. ${ }^{3}$ The death in her case, therefore, may well have been in a patient in whom the plasma cholinesterase was deficient in quality or quantity and may have been further reduced by the amitryptiline. In this context, therefore, anxiety would have played no part. In fact plasma cholinesterase is very often raised rather than lowered in anxiety states. ${ }^{4}-\mathrm{I}$ am, etc.

Alan A. MORgan Medical Adviser,
Allbright and Wilson Ltd.

Ilford, Essex

Hodges, R. J. H., and Harkness, J., British Medical Fournal, 1954, 2, 18

2 Harris, H., Proceedings of the Royal Society of Medicine, 1964, 57, 503 .

3 Kalow, w., Genest, K., and Staron, N., Canadian fournal of Biochemistry and Physiology. 1956,

4 34, 637. Davies, D. A., and Lehmann, H., Lancet, 1965, 2, 563. 